\title{
TINJAUAN PENGARUH PERUBAHAN DIMENSI PONDASI KAPAL IKAN TRADISIONAL TERHADAP NILAI AMPLITUDO GETARAN
}

\author{
D. R. Lekatompessy ${ }^{1, *}$ \\ 1Jurusan Teknik Perkapalan Fakultas Teknik Universitas Pattimura, Ambon 97234 \\ *debby.lekatompessy@fatek.unpatti.ac.id
}

\begin{abstract}
Abstrak. Penelitian ini bertujuan untuk memperoleh dimensi pondasi baru dan juga menggunakan karet peredam sebagai solusi paling sederhana dalam mengatasi masalah getaran yang berlebih pada sistem, sesuai standar yang diijinkan. Dari analisis perhitungan dapat disimpulkan bahwa untuk mengatasi kelebihan getaran yang terjadi dapat dilakukan dengan memperbesar, atau merubah bentuk, dimensi dari pondasi, serta redaman (c) dari pondasi tersebut. Besar amplitudo getaran pada sistem pondasi motor penggerak pada kapal ini adalah 0,078 $\mathrm{mm}$ untuk tipe SR1110 dan 0,069 mm untuk tipe S1100 dan tingkat getaran yang terjadi dinyatakan masih melebihi dari batasan. Dengan perubahan dimensi pondasi yang baru, besar amplitudo untuk mesin diesel tipe SR1110 menjadi 0,0245 mm dan tipe S1 100 menjadi 0,0238 mm. Perbandingan hasil tersebut dengan tabel Barkan menunjukkan bahwa nilai amplitudo ini masih dalam batas yang diijinkan yaitu kurang dari $0,02 \mathrm{~mm} \mathrm{~s} / \mathrm{d}$ $0,05 \mathrm{~mm}$.
\end{abstract}

Kata kunci: Outboard engine, kekakuan, redaman, transmisibilitas.

\begin{abstract}
This research aims to obtain new foundation dimensions and also use rubber dampers as the most straightforward solution in overcoming the problem of excessive vibration in the system, according to permitted standards. From the calculation analysis, it can be concluded that to overcome the excess vibration that occurs can be done by enlarging or changing the shape, dimensions of the foundation, and damping (c) of the foundation. The magnitude of the vibration amplitude in the driving motor foundation system on this ship is $0.078 \mathrm{~mm}$ for the SR1110 type and $0.069 \mathrm{~mm}$ for the S1100 type and the vibration level that occurs is stated to exceed the limits still. With the change in the dimensions of the new foundation, the amplitude of the SR1110 type diesel engine becomes $0.0245 \mathrm{~mm}$ and the $S 1100$ type becomes $0.0238 \mathrm{~mm}$. A comparison of these results with the Barkan table shows that the value of this amplitude is still within the allowable limit of less than $0.02 \mathrm{~mm}$ to $0.05 \mathrm{~mm}$.
\end{abstract}

Keywords: Outboard engine, stiffness, damping, transmissibility

\section{PENDAHULUAN}

Sebagian masyarakat di daerah pantai bermata pencarian sebagai nelayan. Para nelayan ini melakukan usaha penangkapan ikan secara tradisional dengan menggunakan kapal yang dilengkapi motor penggerak dan jaring sebagai alat tangkapnya dengan tidak memperhitungkan daya mesin [1]. Pada umumnya mereka menggunakan motor penggerak jenis diesel. Sistem pemasangan antara lain sistem outboard engine, inboard engine dan gabungan. Nelayan daerah, sebagian besar menggunakan sistem outboard engine. Pemasangan motor penggerak sistem outboard engine dilakukan dengan peletakkan motor penggerak dan pondasinya di atas balok, di atas dek dan diikat dengan plat yang ditancapkan dalam balok tersebut. Poros dari sistem propulsi yang menghubungkan antara mesin dengan propeller dapat diangkat dan diturunkan. Kondisi seperti ini memungkinkan terjadi getaran yang berlebih pada pondasi dan balok pengikat sehingga dapat merusak pondasi itu sendiri dan dapat mengancam keselamatan pengemudinya.

Perencanaan yang dilakukan oleh nelayan dengan meletakkan posisi motor penggerak di atas 
(outboard engine) adalah agar memudahkan mereka dalam pengoperasian maupun perawatan. Peletakan motor pada posisi ini tidak memperhitungkan aspek getaran yang akan timbul dan akibatnya pada pondasi motor penggerak itu sendiri. Walau ada penelitian mengenai stabilitas mengenai tipe mesin ini [2], tetapi getaran yang diakibatkannya belum ditinjau. Berdasarkan uraian diatas maka telah dilakukan eksperimen untuk menganalisa getaran pondasi motor penggerak kapal ikan tradisional tipe outboard engine, sebagaimana penelitian getaran sebelum terhadap tipe ini terbukti menghasilkan getaran jauh di atas standar yang diijinkan. Untuk menindak lanjuti penelitian ini maka diperlukan solusi untuk mengurangi getaran sampai kepada batas aman yang diijinkan [3]. Dengan menggunakan data eksperimen yang ada untuk tipe ini maka diperlukan dimensi pondasi baru dan penggunaan redaman melalui perhitungan secara teoritis [4].

\section{BAHAN DAN METODE 2.1. Umum}

Metode yang akan digunakan dalam penelitian ini adalah dengan mengambil data dari eksperimen yang telah dibuat, kemudian dihitung berdasarkan rumus-rumus teoritis. Dari eksperimen diperoleh besar nilai amplitudo getaran kemudian hasilnya dihitung berdasarkan rumus-rumus teoritis dan dibandingkan dengan standar batasan getaran.

Dalam melakukan penelitian ini dipakai pondasi motor penggerak kapal ikan tradisional tipe outboard engine, motor penggerak yang digunakan yaitu jenis motor diesel putaran tinggi dua buah. Dua motor diesel tersebut yang datanya akan digunakan dalam perhitungan getaran. Motor diesel tersebut masing masing memiliki putaran di atas $2000 \mathrm{rpm}$.

\subsection{Studi Literatur}

Studi literatur dilakukan untuk mendapatkan literatur-literatur atau referensi tentang semua yang berhubungan dengan analisa getaran ini. Studi literatur diperoleh dari buku teks, laporan penelitian, jurnal, yang materinya masih bersangkutan dengan masalah ini dan menunjang penelitian.

\subsection{Titik Pengukuran}

Ada 6 posisi titik pengukuran yaitu dua pada posisi engine dimana posisi tersebut berada didekat dengan pergerakan piston, tiga posisi pondasi diambil rata (kanan, kiri dan tengah) dan satu titik di lantai atau balok pondasi.

\subsection{Pengukuran Getaran}

Dalam pengukuran didapatkan nilai Amplitudo getaran dan parameter-parameter getaran yang lain dengan melihat respon dari grafik getaran yang dihasilkan. Pengukuran yang telah dilakukan pada beberapa tingkat rpm tertentu yaitu dari rpm minimum hingga maksimum. Tingkatan rpm yang diambil adalah 550, 1100, 1650, $2200 \mathrm{rpm}$. Adapun spesifikasi dari motor diesel tersebut sebagaimana pada Tabel 1.

Tabel 1. Spesifikasi motor diesel yang digunakan

\begin{tabular}{|c|c|c|c|}
\hline No. & Spesifikasi & Motor Diesel 1 & Motor Diesel 2 \\
\hline 1. & Merek & Dongfeng & Dongfeng \\
\hline 2. & Type & $\begin{array}{l}\text { SR1110 single- } \\
\text { cylinder, } \\
\text { horizontal, } \\
\text { four-stroke }\end{array}$ & $\begin{array}{l}\text { S1100 Single } \\
\text { cylinder, } \\
\text { horisontal, four } \\
\text { stroke }\end{array}$ \\
\hline 3. & Kecepatan & $2200 \mathrm{rpm}$ & $2200 \mathrm{rpm}$ \\
\hline 4. & Daya Output & $14.7 \mathrm{~kW}$ & $16 \mathrm{hp}$ \\
\hline 5. & Gross Weight & $215 \mathrm{~kg}$ & $190 \mathrm{~kg}$ \\
\hline
\end{tabular}

\subsection{Melakukan perhitungan}

Dari hasil pengukuran getaran didapatkan beberapa variabel getaran baik amplitudo, frekuensi maupun variabel yang lain. Variabel yang diambil dalam penelitian ini adalah amplitudo getaran, untuk menentukan nilai-nilai berikut:

a) Gaya eksitasi dari motor diesel

Perhitungan gaya eksitasi ditentukan berdasarkan persamaan sebagai berikut:

$$
X=\frac{\frac{F_{0}}{k}}{\sqrt{\left(1-\frac{m \omega^{2}}{k}\right)^{2}+\left(\frac{c \omega}{k}\right)^{2}}}=\frac{\frac{F_{0}}{k}}{\sqrt{\left[1-\left(\frac{\omega}{\omega_{n}}\right)^{2}\right]^{2}+\left[2 \zeta \frac{\omega}{\omega_{n}}\right]^{2}}}
$$

dimana: $X=$ amplitudo getaran $(\mathrm{mm})$

$F_{0}=$ besar gaya eksitasi $(\mathrm{N})$

$\mathrm{k}=$ konstanta pegas $(\mathrm{N} / \mathrm{m})$

$\mathrm{m}=$ massa sistem $(\mathrm{kg})$

$\mathrm{c}=$ koefisien peredam $(\mathrm{kg} / \mathrm{s})$

$\zeta=$ faktor redaman (rasio redaman)

$\omega=$ frekuensi gaya eksitasi $(\mathrm{Hz})$

$\omega_{\mathrm{n}}=$ frekuensi natural sistem $(\mathrm{Hz})$

Massa sistem didapat dari persamaan:

$$
\begin{aligned}
m= & m_{m}+m_{k} \\
\text { dimana: } & m_{m}=\text { massa mesin }(\mathrm{kg}) \\
& m_{k}=\text { massa kanal }(\mathrm{kg})
\end{aligned}
$$

Kekakuan dihitung dengan persamaan:

$$
k=(3 E I) /(l+a) a^{2}
$$


$E=$ modulus elastisitas pondasi $\left(\mathrm{N} / \mathrm{m}^{2}\right)$

$I=$ momen inersia pondasi $\left(\mathrm{m}^{4}\right)$

$l$ =panjang pondasi yang menyangga mesin (panjang dari tumpuan sampai ikatan)

$a$ =panjang pondasi dari tumpuan ke depan

Sementara, redaman $(c)$ dihitung dengan persamaan:

$$
c=\sqrt{E I / \rho A} \text { [5] }
$$

dimana:

$E=$ modulus elastisitas pondasi $\left(\mathrm{N} / \mathrm{m}^{2}\right)$

$I=$ momen inersia pondasi $\left(m^{4}\right)$

$\rho=$ massa jenis pondasi $\left(\mathrm{kg} / \mathrm{m}^{3}\right)$

$A=$ luas penampang dari pondasi $\left(\mathrm{m}^{2}\right)$

Redaman kritis $\left(c_{c r}\right)$ dihitung dengan persamaan:

$$
c_{c r}=2 \sqrt{ } k_{m}
$$

Sehingga faktor redaman $\zeta$ diperoleh dari:

$$
\zeta=\frac{c}{c_{c r}}
$$

Frekuensi eksitasi $(\omega)$ didapatkan dari persamaan:

$$
\omega=\frac{2 . \pi \cdot n}{60}
$$

Dan frekuensi natural $\left(\omega_{n}\right)$ sistem dipengaruhi oleh nilai $k$ dan $m$ :

$$
\omega_{n}=\sqrt{\frac{k}{m}}
$$

\section{b) Transmisibilitas}

Transmibilitas (daya hantar) pada dasarnya adalah rasio dari gaya yang diteruskan lewat pegas dan peredam $\left(F_{T}\right)$ dengan gaya perangsang yang bekerja pada $\operatorname{sistem}\left(F_{o}\right)$. Dihitung dengan persamaan:

$$
X=\frac{F_{T}}{F_{0}} \frac{\sqrt{1+\left(\frac{\omega c}{k}\right)^{2}}}{\sqrt{\left(1-\frac{m \omega^{2}}{k}\right)^{2}+\left(\frac{c \omega}{k}\right)^{2}}}=\frac{\sqrt{1+\left(2 \zeta \frac{\omega}{\omega_{n}}\right)^{2}}}{\sqrt{\left[1-\left(\frac{\omega}{\omega_{n}}\right)^{2}\right]^{2}+\left[2 \zeta \frac{\omega}{\omega_{n}}\right]^{2}}}
$$

c) Besarnya gaya yang diteruskan ke balok pondasi

Gaya yang diteruskan ke balok pondasi dapat dihitung berdasarkan perkalian antara besar gaya eksitasi (F0) dengan besar transmibilitas (TR). Lebih jelasnya dapat dituliskan seperti rumus dibawah ini :

$$
F_{T R}=F_{0} \times T R
$$

\subsection{Perbandingan dengan Standar yang Berlaku}

Tingkat getaran pada suatu mesin akan mempengaruhi kerja sistem permesinan itu sendiri, dan dapat mempengaruhi kesehatan bagi operator mesin, oleh sebab itu tingkat getaran pada mesin harus dibatasi, sehingga keamanan dan kenyamanan bagi operator dan sistem dapat terjaga.

Hasil dari pengukuran dibandingkan dengan standar batasan getaran, standart yang digunakan berupa grafik batasan getaran yang diijinkan untuk struktural damage, machinery vibration dan human perception.

\subsection{Solusi untuk Mengurangi Getaran}

Dengan data besar amplitudo dan besarnya getaran yang diteruskan ke pondasi maka dibuat dimensi baru pondasi dan juga ditambahkan peredam dalam hal ini karet dengan ukuran sesuai hasil perhitungan dengan memperhatikan nilai c dan $k$. Selain perhitungan-perhitungan diatas juga dilakukan perhitungan hubungan antara nilai $c, k$ dengan amplitudo.

\section{HASIL DAN PEMBAHASAN 3.1. Perhitungan Getaran Pondasi Terpasang}

a) Motor diesel 1, Dongfeng tipe SR1110

Tabel 2. Hasil pengukuran amplitudo Dongfeng tipe SR1110

\begin{tabular}{ccccccc} 
rpm & $\begin{array}{c}\text { Titik } \\
\text { A } \\
(\mathrm{mm})\end{array}$ & $\begin{array}{c}\text { Titik } \\
\text { B } \\
(\mathrm{mm})\end{array}$ & $\begin{array}{c}\text { Titik } \\
\text { C } \\
(\mathrm{mm})\end{array}$ & $\begin{array}{c}\text { Titik } \\
\text { D } \\
(\mathrm{mm})\end{array}$ & $\begin{array}{c}\text { Titik } \\
(\mathrm{mm})\end{array}$ & $\begin{array}{c}\text { Titik } \\
(\mathrm{mm})\end{array}$ \\
\hline 550 & 0.078 & 0.072 & 0.071 & 0.058 & 0.058 & 0.027 \\
1100 & 0.073 & 0.062 & 0.064 & 0.060 & 0.058 & 0.029 \\
1650 & 0.064 & 0.062 & 0.062 & 0.061 & 0.058 & 0.030 \\
2200 & 0.062 & 0.060 & 0.061 & 0.058 & 0.057 & 0.029 \\
\hline
\end{tabular}

Ket :

$\checkmark$ Titik A,B pada posisi sekitar mesin

$\checkmark \quad$ Titik C,D,E pada posisi sekitar pondasi

$\checkmark \quad$ Titik F pada posisi sekitar balok pondasi

b) Motor diesel 2, Dongfeng tipe $S 1100$

Tabel 3. Hasil pengukuran amplitudo Dongfeng tipe $\mathrm{S} 1100$

\begin{tabular}{ccccccc}
\hline rpm & $\begin{array}{c}\text { Titik } \\
\text { A } \\
(\mathrm{mm})\end{array}$ & $\begin{array}{c}\text { Titik } \\
\text { B } \\
(\mathrm{mm})\end{array}$ & $\begin{array}{c}\text { Titik } \\
(\mathrm{mm})\end{array}$ & $\begin{array}{c}\text { Titik } \\
\text { D } \\
(\mathrm{mm})\end{array}$ & $\begin{array}{c}\text { Titik } \\
(\mathrm{mm})\end{array}$ & $\begin{array}{c}\text { Titik } \\
(\mathrm{mm})\end{array}$ \\
\hline 550 & 0.069 & 0.064 & 0.062 & 0.060 & 0.052 & 0.026 \\
1100 & 0.066 & 0.064 & 0.062 & 0.058 & 0.060 & 0.025 \\
1650 & 0.064 & 0.063 & 0.062 & 0.055 & 0.058 & 0.026 \\
2200 & 0.060 & 0.058 & 0.058 & 0.055 & 0.053 & 0.025 \\
\hline
\end{tabular}

Keterangan:

$\checkmark$ Titik A,B pada posisi sekitar mesin 
$\checkmark \quad$ Titik C,D,E pada posisi sekitar pondasi

$\checkmark \quad$ Titik F pada posisi sekitar balok pondasi

\subsection{Perhitungan Getaran}

\subsubsection{Perhitungan Gaya eksitasi}

a. Perhitungan gaya eksitasi pada mesin diesel dongfeng tipe SR1110

Mesin diesel ini merupakan salah satu motor penggerak yang terletak pada posisi portside kapal. Berdasarkan pada persamaan (2), massa sistem diperoleh sebesar:

$$
m=215+15=230 \mathrm{~kg}
$$

Dengan persamaan (3), diperoleh nilai kekakuan $(k)$ adalah:

$$
k=27.294 \times 10^{6} \mathrm{~N} / \mathrm{m}
$$

Nilai redaman diperoleh dengan persamaan (4), yaitu

$$
c=501.387 \mathrm{Kg} / s .
$$

Selanjutnya, nilai redaman kritis didapat dari persamaan (5):

$$
c_{c r}=158461.85 \mathrm{Kg} / \mathrm{s}
$$

Sehingga rasio redaman didapat engan persamaan (6), yaitu:

$$
\xi=0.00316
$$

dengan persamaan (7) didapatkan nilai frekuensi eksitasi didapatkan dari rumus:

$$
\omega=36.667 \mathrm{~Hz}
$$

serta frekuensi natural $\left(\omega_{n}\right)$ sistem:

$$
\omega_{n}=54.854 \mathrm{~Hz}
$$

Besar amplitudo getaran $(X)$ dari hasil percobaan pada motor diesel dongfeng tipe SR1110 adalah $0.078 \mathrm{~mm}$. Berdasarkan nilai-nilai diatas, nilai $F_{0}$ (gaya eksitasi) dapat dihitung dengan persamaan (1), diperoleh besar Gaya eksitasi pada motor diesel Dongfeng tipe SR1110 adalah $1177.711 \mathrm{~N}$.

\section{b. Perhitungan gaya eksitasi pada mesin diesel dongfeng tipe S1100.}

Mesin diesel ini merupakan salah satu motor penggerak yang terletak pada posisi starboard kapal. Pada mesin diesel ini diperoleh massa sistem sebesar:

$$
m=190+15=205 \mathrm{~kg}
$$

Kedua sistem memiliki nilai $k$ dan $c$ yang sama karena bentuk pondasi memiliki ukuran yang sama. Redaman kritis dari sistem yang kedua ini adalah

$$
c_{c r}=149602.12 \mathrm{Kg} / \mathrm{s}
$$

jadi rasio redamannya adalah:

$$
\zeta=0.00335
$$

Frekuensi eksitasi $\omega$ didapatkan dari rumus $\omega=36.667 \mathrm{~Hz}$

Frekuensi natural sistem $\omega_{n}$ dipengaruhi oleh nilai $k$ dan $m$

$$
\omega_{n}=364.883 \mathrm{rad} / \mathrm{s}=58.102 \mathrm{~Hz}
$$

Besar amplitudo getaran $(X)$ dari hasil percobaan pada motor diesel dongfeng tipe S1100 adalah 0.069 mm. Berdasarkan nilai-nilai diatas untuk mendapatkan nilai $F_{0}$ (gaya eksitasi) dapat dihitung dengan persamaan (1), diperoleh besar gaya eksitasi pada motor diesel Dongfeng tipe S 1100 adalah sebesar $1133.280 \mathrm{~N}$.

\subsubsection{Perhitungan Transmibilitas}

a. Perhitungan transmibilitas untuk sistem pondasi pada mesin diesel Dongfeng tipe SR1110

Besarnya transmisibilitas (daya hantar) berdasarkan persamaan (9) adalah $T R=1.808$

b. Perhitungan transmibilitas untuk sistem pondasi pada mesin diesel Dongfeng tipe $\$ 1100$

Besarnya transmibilitas (daya hantar) berdasarkan persamaan (9) adalah $T R=1.662$

\subsubsection{Perhitungan Gaya Yang Diteruskan Ke Balok Pondasi}

a. Pada mesin diesel dongfeng tipe SR1110

Gaya yang diteruskan ke balok pondasi sesuai persamaan (10) adalah sebesar $F_{T R}=2128.924 \mathrm{~N}$

b. Pada mesin diesel dongfeng tipe $\$ 1100$

Gaya yang diteruskan ke balok pondasi sesuai persamaan (10) adalah sebesar $F_{T R}=1883.277 \mathrm{~N}$

\subsection{Pengamatan Terhadap Bentuk Pondasi}

Bentuk pondasi pada pada motor penggerak pada kapal ini dari dua mesin yang ada, hampir memiliki karakteristik yang sama. Pada pengamatan ini ditekankan bagaimana bentuk dari pondasi yang digunakan pada diesel SR1110 maupun diesel tipe S1100. Pondasi selain memiliki fungsi sebagai penyangga mesin juga digunakan sebagai penyangga shaft propeller yang langsung terhubung dengan roda gila dari mesin diesel itu sendiri.

Karakteristik dari sistem pondasi kapal ini adalah:

a. Pondasi mesin pada kapal ini berbentuk profil U.

b. Pondasi ini diikat langsung dengan mesin dengan baut tanpa ada pemberian bahan peredam berupa karet. 


\subsection{Perbandingan Besar Getaran Dengan Standar}

Perbandingan besar getaran yang terjadi dengan standar yang ada ini dimaksudkan untuk mengetahui apakah getaran yang terjadi sudah diijinkan atau melampaui batas yang diijinkan. Batasan yang di gunakan adalah dengan mengacu pada grafik pada Gambar 2, dengan nilai frekuensi dan amplitudo sebagai input.

Berdasarkan nilai frekuensi sebesar $36.667 \mathrm{~Hz}$ dan amplitudo sebesar $0.078 \mathrm{~mm}$ atau $78 \mu \mathrm{m}$ (untuk diesel tipe SR1110) dapat ditarik garis ke atas, dan hasilnya diatas garis putus-putus impermissible. Jadi pada kasus sistem pondasi diesel tipe SR1110 getaran yang terjadi sudah melampaui dari yang diijinkan.

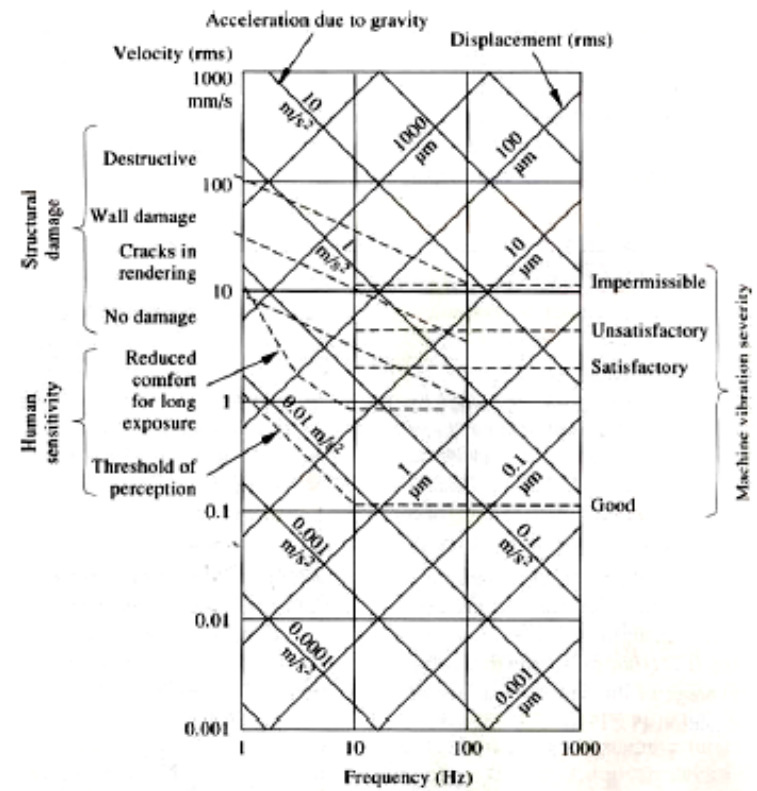

Gambar 2. Grafik batasan yang diijinkan untuk structural damage, machinery vibration dan human perception. [5]

Sedangkan untuk tipe S1100 dengan nilai frekuensi sebesar $36.667 \mathrm{~Hz}$ dan amplitudo sebesar $0.069 \mathrm{~mm}$ atau $69 \mu \mathrm{m}$ dapat ditarik garis keatas, dan hasilnya diatas garis putus-putus impermissible. Pada kasus sistem pondasi diesel tipe S1100 getaran yang terjadi sudah melampaui dari yang diijinkan.

Batasan yang kedua yaitu digunakan tabel batasan getaran pada mesin, ditunjukkan pada Tabel 4, dimana dalam tabel ini ada batasan batasan getaran yang harus dipenuhi oleh mesin baik yang low speed maupun yang high speed. Adapun dalam tabel ini yang menjadi input adalah besar nilai amplitudo.

Berdasarkan Tabel 4, pada No.3a yaitu high speed machinery vertical vibration. Berdasarkan acuan tersebut nilai getaran yang terjadi sudah tidak terpenuhi, baik SR1110 maupun S1100, karena nilai amplitudo sudah melampaui dari batas ijin yaitu $0.002 \mathrm{~cm}-0.003 \mathrm{~cm}$.

Tabel 4. Permissible amplitude untuk mesin [6]

\begin{tabular}{|c|c|c|}
\hline & Type & $\begin{array}{c}\text { Permissible } \\
\text { Amplitudo }(\mathrm{cm})\end{array}$ \\
\hline 1) & 1.Low speed machinery (500 rpm) & $0,02-0,025$ \\
\hline 2) & 2.Hammer Fondations & $0,1-0,12$ \\
\hline & $\begin{array}{l}\text { 3.High Speed machinery } \\
\text { a. } 3000 \mathrm{rpm}\end{array}$ & \\
\hline & - Vertical vibrations & $0,002-0,003$ \\
\hline & - Horizontal vibrations & $0,004-0,005$ \\
\hline & b. $1500 \mathrm{rpm}$ & \\
\hline & - Vertical vibrations & $0,004-0,006$ \\
\hline & - Horizontal vibrations & $0,007-0,009$ \\
\hline
\end{tabular}

\subsection{Penurunan Getaran Pondasi dengan Memperbesar Nilai $k$ dan $c$}

Metode penurunan getaran yang digunakan dalam penelitian ini adalah dengan merancang nilai $c$ dan $k$ untuk menurunkan getaran yang berlebih. Untuk melakukan penurunan getaran yang terjadi pada sistem ini diperlukan perancangan nilai $c$ dan $k$ yang bagus sehingga didapatkan bentuk pondasi yang mampu menopang, menghantar dan meredam mesin diesel ini dengan bagus. Dengan merancang nilai $c$ dan $k$ yang bagus kita dapat menurunkan besar amplitudo yang terjadi sebelumnya sehingga tingkat getaran yang terjadi dapat diatasi. Adapun perancangan nilai $\mathrm{k}$ adalah sebagaimana perhitungan pada Tabel 5.

Tabel 5. Hubungan variasi nilai $k$ dan $x$ pada sistem pondasi

\begin{tabular}{cccc}
\multicolumn{2}{c}{ Tipe SR1110 } & \multicolumn{2}{c}{ Tipe S1110 } \\
$k$ & $\boldsymbol{X}(\mathrm{mm})$ & $k$ & $\boldsymbol{X}(\mathrm{mm})$ \\
\hline $2.73 \mathrm{E}+07$ & 0.078 & $2.73 \mathrm{E}+07$ & 0.069 \\
$3.00 \mathrm{E}+07$ & 0.066 & $3.00 \mathrm{E}+07$ & 0.059 \\
$4.00 \mathrm{E}+07$ & 0.042 & $4.00 \mathrm{E}+07$ & 0.039 \\
$5.00 \mathrm{E}+07$ & 0.031 & $5.00 \mathrm{E}+07$ & 0.029 \\
$6.00 \mathrm{E}+07$ & 0.025 & $6.00 \mathrm{E}+07$ & 0.023 \\
$7.00 \mathrm{E}+07$ & 0.020 & $7.00 \mathrm{E}+07$ & 0.019 \\
$8.00 \mathrm{E}+07$ & 0.017 & $8.00 \mathrm{E}+07$ & 0.016 \\
$9.00 \mathrm{E}+08$ & 0.015 & $9.00 \mathrm{E}+08$ & 0.014 \\
$1.00 \mathrm{E}+08$ & 0.013 & $1.00 \mathrm{E}+08$ & 0.013 \\
\hline
\end{tabular}

Dengan melihat perhitungan diatas bahwa nilai $\mathrm{k}$ sebelumnya adalah sebesar. $2.73 \times 10^{7}$ dan nilai amplitudonya sebesar $0.078 \mathrm{~mm}$. Dengan merancang nilai $k$ yang lebih besar akan dapat menurunkan besar amplitudo. Sedangkan perancangan nilai $c$ ditunjukkan pada Tabel 6 . 


\subsection{Pemilihan Dimensi Pondasi dan Peredam}

Perancangan nilai $c$ dan $k$ juga ada batasannya, karena dengan merancang sebesar-besarnya dapat mempengaruhi bentuk dari pondasi itu sendiri, misalnya perancangan $c$ dengan menggunakan bahan rubber dengan merancang nilai $c$ yang besar maka bentuk dari rubber pun harus semakin besar. Batasan ini juga dimaksudkan untuk estetika dan kenyamanan pengguna.

Adapun perhitungan dari perubahan perancangan nilai $c$ dan $k$. Perhitungan yang digunakan disini adalah pada sistem pondasi motor penggerak tipe SR1110 dan S1100 adalah sebagai berikut; Dengan merubah bentuk dimensi dari penampang pondasi sebagaimana gambar dibawah ini. Berdasarkan perhitungan nilai $k$ dari penampang pondasi tersebut adalah sebesar $5.837 \times 10^{7} \mathrm{~N} / \mathrm{m}$.

Tabel 6. Hubungan variasi nilai $c$ dan $x$ untuk nilai $k=2.73 \times 10^{7}$

\begin{tabular}{llll}
\hline \multicolumn{2}{c}{ Tipe SR1110 } & \multicolumn{2}{c}{ Tipe S1110 } \\
\multicolumn{1}{c}{$c$} & $\boldsymbol{X}(\mathrm{mm})$ & \multicolumn{1}{c}{$c$} & $\boldsymbol{X}(\mathrm{mm})$ \\
\hline 501.38697 & 0.078 & 501.38697 & 0.069 \\
1000 & 0.078 & 1000 & 0.069 \\
2000 & 0.078 & 2000 & 0.069 \\
3000 & 0.078 & 3000 & 0.069 \\
4000 & 0.078 & 4000 & 0.069 \\
5000 & 0.078 & 5000 & 0.069 \\
6000 & 0.078 & 6000 & 0.069 \\
7000 & 0.078 & 7000 & 0.069 \\
8000 & 0.077 & 8000 & 0.069 \\
9000 & 0.077 & 9000 & 0.068 \\
10000 & 0.077 & 10000 & 0.068 \\
\hline
\end{tabular}

Tabel 7. Hubungan variasi nilai $c$ dan $x$ untuk nilai $k=3.00 \times 10^{7}$

\begin{tabular}{cccc}
\hline \multicolumn{2}{c}{ Tipe SR1110 } & \multicolumn{2}{c}{ Tipe S1110 } \\
$c$ & $\boldsymbol{X}(\mathrm{mm})$ & $c$ & $\boldsymbol{X}(\mathrm{mm})$ \\
\hline 1000 & 0.0661 & 1000 & 0.0592 \\
2000 & 0.0661 & 2000 & 0.0592 \\
3000 & 0.0661 & 3000 & 0.0592 \\
4000 & 0.0661 & 4000 & 0.0592 \\
5000 & 0.0660 & 5000 & 0.0591 \\
6000 & 0.0659 & 6000 & 0.0591 \\
7000 & 0.0659 & 7000 & 0.0590 \\
8000 & 0.0658 & 8000 & 0.0590 \\
9000 & 0.0657 & 9000 & 0.0589 \\
10000 & 0.0656 & 10000 & 0.0588 \\
\hline
\end{tabular}

Dengan memberi bahan peredam berupa karet dengan $E=2.3 \times 10^{9}$ dan $\rho=1100$ (Inman Daniel J, 1996) yang memiliki penampang sebagaimana gambar dibawah ini. Berdasarkan perhitungan nilai $c$ dari penampang peredam tersebut adalah sebesar $7634.867 \mathrm{~kg} / \mathrm{s}$.

Berdasarkan perhitungan pada perubahan bentuk pondasi didapat hubungan nilai $c, k$ dan $X$ dapat dilihat pada Tabel 8.

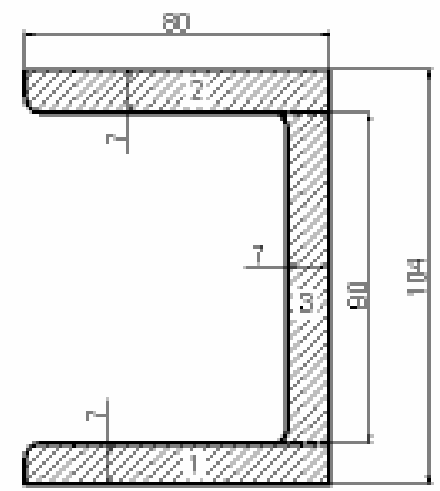

Gambar 3. Penampang pondasi

80

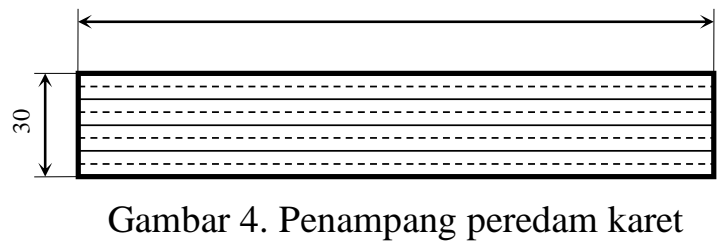

Tabel 8. Hubungan nilai $k, c$ dan $X$

\begin{tabular}{cccccc}
\hline$k$ & $c$ & $\begin{array}{c}\boldsymbol{X}_{\text {lama }} \\
(\mathrm{mm})\end{array}$ & $\begin{array}{c}\boldsymbol{X}_{\text {baru }} \\
(\mathrm{mm})\end{array}$ & $\begin{array}{c}\boldsymbol{X}_{\text {lama }} \\
(\mathrm{mm})\end{array}$ & $\begin{array}{c}\boldsymbol{X}_{\text {baru }} \\
(\mathrm{mm})\end{array}$ \\
\hline $5.837 \times 10^{7}$ & 7634.867 & 0.078 & 0.0245 & 0.069 & 0.0238 \\
\hline
\end{tabular}

Disini terlihat bahwa nilai amplitudo yang terjadi lebih kecil dibandingkan sebelumnya dan memenuhi standar.

\subsection{Analisa Getaran}

Berdasarkan hasil perbandingan getaran yang terjadi kita juga bisa melihat bahwa besar getaran yang terjadi sudah tidak memenuhi atau lebih dari batas yang diijinkan. Permasalahan getaran yang sangat besar ini diakibatkan karena tidak diterapkan isolasi yang bagus pada sistem ini. Untuk mendapatkan isolasi yang bagus pada sistem ini diperlukan perencanaan sistem pondasi yang benarbenar bisa menghantarkan dan meredam getaran yang ditimbulkan oleh mesin ke kapal.

Besar amplitudo getaran yang terjadi dapat dikurangi dengan menopang mesin pada massa besar. Perencanaan sistem pondasi yang bagus agar getaran tersebut terkurangi adalah dengan 
menambah massa penopang yang lebih besar dari sebelumnya. Penambahan tersebut akan merubah bentuk dimensi dari penopang sendiri dan otomatis nilai $k$ akan bertambah besar. Dengan bertambahnya nilai $k$ tersebut besar amplitudo getaran yang terjadi akan dapat terkurangi. Untuk melakukan penurunan terhadap besar amplitudo getaran yang terjadi, selain menambah besar nilai $k$ juga dilakukan pemberian nilai $c$ sebagai redaman.

Jadi untuk mengurangi getaran besar yang terjadi pada kasus ini, selain dengan merancang besar nilai $c$ dan $k$ tersebut adalah juga dengan merancang sistem pengikatan dan sistem engsel pondasi yang lebih baik sehingga getaran yang terjadi dapat tersalurkan merata ke badan kapal.

\section{KESIMPULAN}

Berdasarkan hasil perbandingan getaran yang terjadi kita juga bisa melihat bahwa besar getaran yang terjadi sudah tidak memenuhi atau lebih dari batas yang diijinkan. Permasalahan getaran yang sangat besar ini diakibatkan karena tidak diterapkan isolasi yang bagus pada sistem ini. Untuk mendapatkan isolasi yang bagus pada sistem ini diperlukan perencanaan sistem pondasi yang benarbenar bisa menghantarkan dan meredam getaran yang ditimbulkan oleh mesin ke kapal.

Besar amplitudo getaran yang terjadi dapat dikurangi dengan menopang mesin pada massa besar. Perencanaan sistem pondasi yang bagus agar getaran tersebut terkurangi adalah dengan menambah massa penopang yang lebih besar dari sebelumnya. Penambahan tersebut akan merubah bentuk dimensi dari penopang sendiri dan otomatis nilai k akan bertambah besar. Dengan bertambahnya nilai $\mathrm{k}$ tersebut besar amplitudo getaran yang terjadi akan dapat terkurangi. Untuk melakukan penurunan terhadap besar amplitudo getaran yang terjadi, selain menambah besar nilai $\mathrm{k}$ juga dilakukan pemberian nilai c sebagai redaman.

Jadi untuk mengurangi getaran besar yang terjadi pada kasus ini, selain dengan merancang besar nilai $\mathrm{c}$ dan $\mathrm{k}$ tersebut adalah juga dengan merancang sistem pengikatan dan sistem engsel pondasi yang lebih baik sehingga getaran yang terjadi dapat tersalurkan merata ke badan kapal. Penarikan simpulan, perampatan yang meluas, dan pencetusan teori baru yang dituangkan secara mapan menjadikan artikel lebih bermakna dibandingkan dengan memuat tulisan yang berisi simpulan dangkal dan saran bahwa penelitiannya perlu dilanjutkan.
Penelitian ini terlaksana atas bantuan Dana Penelitian yang berasal dari PNBP Fakultas Teknik tahun 2019. Untuk itu, penulis menyampaikan terima kasih kepada Pimpinan Fakultas Teknik Universitas Pattimura.

\section{DAFTAR PUSTAKA}

[1] S. D. Sa'id and M. Ridwan, "Pemilihan Mesin Induk Kapal Purseiner Masyarakat Pesisir Nelayan Pekalongan," J. Pengabdi. Vokasi, vol. 1, no. 2, pp. 99-102, Nov. 2019.

[2] A. P. Wiyastra, M. S. Baskoro, and F. Purwangka, "Instalasi Permesinan pada Kapal PSP 01," J. Teknol. Perikan. Dan Kelaut., vol. 3, no. 1, pp. 35-43, 2012, doi: 10.24319/jtpk.3.35-43.

[3] D. R. Lekatompessy, O. O. Sulaiman, F. Manuhutu, E. J. De Lima, and M. Manuputty, "Rubber as an Effective Vibration Absorber of Outboard Engine at Small Traditional Fishing Boats from the Human Health and Safety Point of View," J. Eng. Comput. Appl. Sci., vol. 2, no. 2, pp. 7-12, Feb. 2013.

[4] L. Xia, W. Wu, C. Weng, and X. Jin, "Analysis of fluid-structure-coupled vertical vibration for high-speed ships," J. Ship Mech., vol. 4, no. 3, pp. 43-50, Dec. 2000.

[5] D. J. Inman, Engineering Vibration, 4th Edition. Pearson, 2013.

[6] P. Srinivasalu and C. Vaidyanathan, Handbook of Machine Foundations, 1 edition. New Delhi: Tata McGraw Hill Education, 1976.

\section{UCAPAN TERIMA KASIH}

